\title{
IEEEVR2020: Exploring the First Steps Toward Standalone Virtual Conferences
}

\section{Sun Joo (Grace) Ahn ${ }^{*}$, Laura Levy ${ }^{2}$, Allison Eden ${ }^{3}$, Andrea Stevenson Won ${ }^{4}$, Blair MacIntyre ${ }^{5}$ and Kyle Johnsen ${ }^{6}$}

${ }^{1}$ Grady College of Journalism \& Mass Communication, University of Georgia, Athens, GA, United States, ${ }^{2}$ Georgia Institute of Technology, Interactive Media Technology Center, Atlanta, GA, United States, ${ }^{3}$ Department of Communication, Michigan State University, East Lansing, MI, United States, ${ }^{4}$ Department of Communication, Cornell University, Ithaca, NY, United States, ${ }^{5}$ College of Computing, Georgia Institute of Technology, Atlanta, GA, United States, ${ }^{6}$ School of Electrical and Computer Engineering, University of Georgia, Athens, GA, United States

The global COVID-19 pandemic forced all large in-person events to pivot to virtual or online platforms. IEEEVR2020 coincided with rising concerns and restrictions on travel and large gatherings, becoming one of the first academic conferences to rapidly adapt its programming to a completely virtual format. The global pandemic provided an impetus to re-examine the possibility of holding social interactions in virtual worlds. This article aims to: (1) revisit the issues of virtual conferences noted in earlier studies, focusing specifically on academic conferences, (2) introduce new survey and observational data from the recent IEEEVR2020 conference, and (3) present insights and future directions for virtual conferences during and after the COVID-19 pandemic. Findings from a field observation during the conference and a post-conference survey point to complex relationships among users, media platforms selected, and social constraints during the virtual conference.

Keywords: social VR, conferences, media appropriateness, social presence, avatars, virtual reality

\section{INTRODUCTION}

The global COVID-19 pandemic forced all large-scale in-person events held in 2020 to move to virtual and online platforms, and academic conferences have been faced with the same need to transition to virtual formats. IEEEVR2020 was the 27th gathering of academics and industry personnel interested in immersive technologies, such as virtual reality and 3D user interfaces. Due to the timing of the conference, which is typically held in late March each year, IEEEVR2020 coincided with rising concerns and restrictions on travel and large gatherings to become one of the first academic conferences to pivot to a completely virtual and online format.

Virtual or online conferences themselves are not new-a small number of conferences in the past have successfully converted in-person events into virtual and online formats (Leong et al., 2008). Particularly when online platforms such as Second Life, a 2-dimensional virtual world for multiple synchronous users, were experiencing their peak popularity with over one million users (Jamison, 2017), moving social interactions into virtual worlds seemed to be a natural next step forward. For a while, research on collaborative virtual environments 
and efforts to host virtual meetings in spaces such as Second Life grew substantially, perhaps fueled by the financial crisis in 2007-2008 that limited travel (Erickson et al., 2011). However, as the economy recovered and travel increased, virtual conferences fell out of favor. In-person travel for meetings and conferences accounted for 135.9 billion U.S. Dollars in direct travel expenditures, taking up $40 \%$ of all business travel in the U.S. in 2019 (U.S. Travel Association, 2017). Despite ongoing concerns about the climate change effects from the footprint of in-person events, and inequities in the ability to travel, there was little reason to change a well-received model of meeting and conferences that played such a critical role in the U.S. economy.

The COVID-19 global pandemic has provided an impetus to re-examine the possibility of holding social interactions in virtual worlds. Thus, an update on the successes and failures of virtual conferences is timely and imperative. As academia grapples with how to connect scholars at a time when in-person contact can result in devastating health risks, this provides an opportunity to consider longer-lasting shifts to the existing model of academic conferences that may persist post-pandemic. This article aims to: (1) revisit the issues of virtual conferences noted in earlier studies, focusing specifically on academic conferences, (2) introduce new survey and observational data from the recent IEEEVR2020 conference, and (3) present insights and future directions for virtual conferences during and after the COVID19 pandemic. While these insights were drawn specifically from an academic conference, the range of activities included in these kinds of events, including listening to talks, sharing research, and formal and informal networking activities, make the discussions presented in this paper broadly relevant.

\section{THE PURPOSE OF ACADEMIC CONFERENCES}

Given the importance and frequency of academic conferences across disciplines, surprisingly little attention has been given to systematically studying the value of academic conferences for participants (Abbey and Link, 1994). In the few papers that have studied academic conferences, authors from a wide range of disciplines acknowledge the critical role that conferences play in academic careers (Zhang et al., 2007; Barnes et al., 2012; Parsons, 2015; Oester et al., 2017; Edelheim et al., 2018; Mair and Frew, 2018). In addition to sharing the most up-to-date knowledge in the field and learning new skills (Rogers, 2012), they provide opportunities for early career researchers to receive advice and mentoring (Parsons, 2015), facilitate faculty recruitment and disseminate job information (Oester et al., 2017), and help academics build social networks (Mair and Thompson, 2009).

At a more casual level, the fun and friendship experienced during academic conferences drive motivation to attend (Mair and Frew, 2018). Despite concerns that the social elements at conferences are irrelevant to work and careers, extensive literature in education notes that enjoying the process of learning is a strong predictor of learning engagement and favorable learning outcomes (Goetz et al., 2006). Similarly, having fun at a conference facilitates the formation of stronger academic networks, fostering collaborations and future productivity (Foley et al., 2014). A number of studies demonstrate that the location of the conference is a strong motivator for attendance because a particularly attractive location can drive motivations to attend (Witt et al., 1995; Mair and Thompson, 2009; Yoo and Zhao, 2010). Heightening motivations to attend is important for academic conferences because the aforementioned benefits of conferencing-sharing knowledge and information, mentoring, and building social networks-are often contingent upon a critical mass of academics attending the event.

\section{THE NECESSITY OF VIRTUAL CONFERENCES}

Unfortunately, the benefits of in-person academic gatherings come at high costs, like other events that require travel. At the individual level, traveling to conferences requires days of disruption to work and personal lives, complex logistical planning for parents or caregivers, and money to cover registration, airfare, mileage, accommodation, and meals (Mair and Frew, 2018). In addition, air travel, in particular, is associated with large ecological footprints that involve significant fossil fuel consumption and greenhouse gas emissions (Høyer and Næss, 2001; Nevins, 2014). Unforeseen circumstances can also unexpectedly impact the feasibility of holding an in-person academic conference, as the recent pandemic has demonstrated.

Yet, pivoting in-person events to virtual or online spaces is not as simple as setting up a few web conferencing calls. In-person conferences involve a complicated array of activities that are both formal and informal, structured and unstructured, synchronous and asynchronous (Sousa and Clark, 2017; Mair and Frew, 2018). No single communication technology has the capability to effectively recreate all of these activities online. Therefore, in order to launch a virtual conference that can successfully carry out the wide range of conference activities, it is important to determine the different types of communication technologies needed, and how suitable each type of communication platform is in meeting the requirements of the task at hand. The concept of media appropriateness (Rice, 1993; Van Den Hooff et al., 2005) proposes that a good match between the characteristics or features of a medium (e.g., interactions with multiple users, synchronicity) and the required task or activity (e.g., knowledge sharing, networking) leads to better performance (e.g., more effective, satisfying experiences). A deeper understanding of this match between technology and task characteristics in the context of virtual academic conferences would provide clear guidelines for hosting and attending such events.

\section{VIRTUAL CONFERENCES THEN AND NOW}

The limited earlier work on virtual conferences has typically focused on the effectiveness of using one communication technology for hosting the conference, typically the most innovative platform available at the time. The Bangkok Project in 1992 was one of the first international virtual conferences supported by the Internet, using e-mail distribution (i.e., listserv) 
to allow scholars attending the International Council for Distance Education conference in person to engage in email discussions before and during the in-person conference (Anderson and Mason, 1993). The same organization in 1995 held another tandem virtual conference alongside the in-person event, where email archives and real-time discussions via multi-user object oriented domains (MOOs) were added to email discussions (Anderson and Mason, 1993). Attendees were generally satisfied with the depth and maturity of the discourse over email and MOO conversations that were made permanently available to attendees, even if they could not travel to the in-person event. However, one of the major problems identified was that attendees rarely had time to digest the flood of information delivered during the virtual portion of the conference and felt overwhelmed at times.

The next wave of interest in virtual conferences for academic gatherings came about with the worldwide economic downturn that began in 2008 that brought about the popularity of the web-based social VR platform, Second Life. In 2010, the global information technology firm IBM hosted their annual technical leadership conference, the Academy General Meeting, in Second Life, in tandem with their in-person meeting. A text-based online discussion forum was also established for communication among attendees during the conference. The virtual conference was set up with separate Second Life areas for the keynote speech, social events, and poster sessions. Around the world, 502 people attended remotely, most returning for the second and third days of the virtual conference (Erickson et al., 2011; Shami et al., 2011). Attendees were largely satisfied with their experiences during the virtual conference, but of the three conference activities, they found poster sessions to be the most effective whereas the keynote speech was least effective. When socializing with others, attendees preferred a highly structured style of social events that mimicked roundtables, rather than freeform events. The authors noted that technical shortcomings, such as the lack of spatial audio and the lack of cues in peripersonal space, may have led to attendees being more comfortable with structured social interactions rather than informal interactions that would rely more heavily on nonverbal social cues.

Another group developed a proprietary web-based social VR platform, similar to Second Life, but tailored to the academic conference environment to include features such as moderation and high resolution slide displays (Shirmohammadi et al., 2012). Based on the earlier findings of the IBM virtual conference, authors posited that the technical shortcomings of their platform did not warrant a completely virtual conference. Instead, they tested the potential of their web-based VR platform as a tandem event that took place alongside the inperson conference to enhance the attendees' experiences at the International Workshop on Massively Multiuser Virtual Environments (MMVE 2010). Results from a post-conference survey revealed that knowledge sharing was effective for both in-person and virtual meetings, which suggests that virtual conferences may serve as a viable alternative for attendees who are unable to physically travel to the in-person event. However, $60 \%$ of the respondents did not meet new people and most attendees did not linger in the virtual world to socialize with other attendees, leading them to feel disconnected and isolated (Shirmohammadi et al., 2012). In 2019, a study examined the potential of using Twitch, a chat application (Discord), and social VR for remote participation in an academic conference with $\sim 150$ participants who did not travel for the in-person event and chose to attend remotely (Le et al., 2020). Findings suggested that these platforms may offer a reasonable alternative to in-person academic conferences, especially if the attendee's primary goal was to learn about new research findings.

In summary, the above summary shows limited but consistent interest in virtual conferences over the past decades. However, prior investigations and discourse on using virtual platforms focused on using virtual elements to enhance or supplement inperson events. The consensus has been that virtual platforms are not feasible or desirable as a standalone conferencing venue. This tendency to consider virtual conference as a supporting element for in-person conferences may be why, despite decades of prior efforts to investigate options to meet virtually, the COVID-19 pandemic was so disruptive to academic conferences-for the first time in history, virtual conferences suddenly had to become the main and only form of conferencing.

\section{IEEEVR2020, A VIRTUAL CONFERENCE OPEN TO EVERYONE}

IEEEVR2020 was the first virtual conference of its kind in terms of the scale and platform options offered to attendees. One of the most unique aspects of IEEEVR2020 that set it apart from its virtual conference predecessors is that it truly took advantage of virtual platforms' ability to provide access to a large number of people. Academic conferences typically have a high entry barrier that silos the produced knowledge among academics, outside of the public's reach. In addition, conferences typically charge hundreds to thousands of U.S. dollars for registration (discounted only for members, who pay hundreds of dollars for memberships) and are hosted in locations that require significant time and money for travel. Virtual conferences can dramatically lower this entry barrier for members of the public who may be interested in the knowledge and expertise being shared, as well as academics who may not have access to the financial resources or social support that enable multiday travel plans. Because the virtual conferences described in our previous section were designed to work in tandem with a parallel in-person event, rather than function as a standalone conference, academic conferences have remained exclusive and insular despite the availability of the virtual conference option.

After becoming an online-only event, IEEEVR2020 drastically transformed its financial model to reflect ongoing circumstances of the global pandemic. Taking into account expected venue cancellation charges, the conference budget shrank to approximately a third of its prior size. After consulting with IEEE and the conference steering committee, the conference moved to a flat fee per contribution (regardless of type), covered entirely by existing author registrations fees, rather than the typical registration-fee system. This was done to make registrations free, with the expectation that this change, alongside 
the notoriety gained by moving a VR conference completely virtual, would greatly increase registrations for the conference, attracting new members to the community and offering authors greater visibility for their contributions. Conservatively, a cap of 1,000 additional registrations (beyond the 550 already registered) was put in place, justified by the largely unknown scalability and reliability of the virtual conferencing technology to be used for the event. This cap was reached within 10 days, and an additional 200 spots were opened up and filled prior to the start of the conference as demand continued to rise and confidence in the technology grew. Additional registrations were processed by various codes (e.g., for sponsors and co-authors), and still more attendees were invited after the conference started. Ultimately, 1,965 attendees were officially registered for the conference along with $\sim 100$ additional unofficial registrations (including some early volunteers, co-authors, guests who failed to register in time), a substantial rise from prior years, with 924 attendees in 2019 and 617 attendees in 2018. This was also an increase of almost three times the pre-transition registration when IEEEVR2020 was planned as an in-person event (Figure 1).

To further lower the barrier for attendance, attendees were able to use a wide range of technology platforms, including Twitch, Slack, Sli.do, Discord, social media (e.g., Twitter, Facebook), and Hubs. Twitch is a live streaming platform that allows large numbers of viewers to simultaneously watch video content and engage in text-based chat while watching. Slack is a text-based relay-chat platform with features that allow for channels, private chatrooms, and direct messaging. Sli.do is an online Q\&A polling platform for live streaming events or virtual meetings through which the attendees can type in questions directly to the presenters. Discord is an instant messaging platform, where users can communicate with voice call, video call, text messaging, and file sharing. Mozilla Hubs is a web-based social VR platform that can be joined from any browser and nearly any internet connected device, including fully immersive VR head-mounted displays, web browsers, and smartphones. Hubs users can customize avatars or choose a pre-formatted one to represent themselves in a three-dimensional virtual space.

Attendees were able to choose any media platform and engage with the conference in any way they desired (e.g., text, live streaming, and virtual reality). The multiple points of access gave attendees the ability to choose from a wide range of technology options to engage in various tasks during the conference. From a research perspective, attendees were given a breadth of platform options, providing a unique and interesting opportunity to observe people's choices of media platforms "in the wild" and how that media platform was appropriate for satisfying the requirements of the conference task at hand (Rice, 1993). Our current research question focuses on the concept of media appropriateness in a large sample of both academic and non-academic attendees, to explore how attendees selected different media platforms to meet their conferencing needs. Understanding the answers to this question will allow us to design effective and accessible virtual conferences that can serve as a standalone event when in-person conferences are not viable or when a virtual conference is more practical or cost-effective than an in-person event:
RQ1: When given the choice, what media platforms do people select to successfully complete different conference tasks?

\section{STUDY OVERVIEW}

The IEEEVR2020 conference was held virtually March 22 through March 26, 2020. This study employed a mixed-method approach by combining quantitative and qualitative data collection methods to explore and assess attendees' experiences during the conference. During the five-day conference, researchers gathered data on attendees' interactions and communication patterns through a field observation in the VR space (Mozilla Hubs). After the conference, all attendees were invited to respond to a post-conference survey, inquiring about their experiences with the range of media platforms offered during the conference. Although the survey data collection took place after the field observation, we present the survey data first for readability.

\section{Survey Procedure and Respondents}

An online survey was sent out to all 1,965 registered attendees to collect data on demographic information, perceptions of importance regarding various conference activities, the appropriateness of different media platforms in meeting the needs of those activities, and overall satisfaction of IEEEVR2020. We received a total of 448 responses, for a response rate of $22.8 \%$. After removing incomplete and duplicate responses, the final sample included 363 responses (corrected response rate $18.5 \%)$.

\section{Survey Measures}

First, findings from earlier studies pointed to five representative conference activities (Zhang et al., 2007; Oester et al., 2017; Edelheim et al., 2018; Mair and Frew, 2018): (1) listening to keynotes, talks, and panels, (2) asking questions of presenters, (3) discussing research ideas with other attendees, (4) socializing and building networks, and (5) learning a new methodological or technical skill. Five 5-point Likert-type items $(1=$ Not important at all; $5=$ Extremely important) were administered to assess attendees' perceived importance of each conference activity.

Conference effectiveness was measured with another set of 5-point Likert-type items that asked attendees how effective IEEEVR2020 was at achieving the same five conference activities $(1=$ Not effective at all; $5=$ Extremely effective $)$.

Media appropriateness was assessed by asking attendees what media platforms they used to participate in the IEEEVR2020 conference (multiple answers were allowed). Then, attendees were asked to respond to five 5-point Likert-type items to assess how appropriate they felt each of the media platform was in completing the five conference activities listed above $(1=$ Not at all appropriate; $5=$ Extremely appropriate).

Attendees also responded to a series of questions asking them about which rooms they visited and their overall satisfaction experienced while visiting these rooms during the conference. The Hubs rooms were created largely for conference or networking functions (Figure 2). Several different types of conference function rooms were available: Hubs 

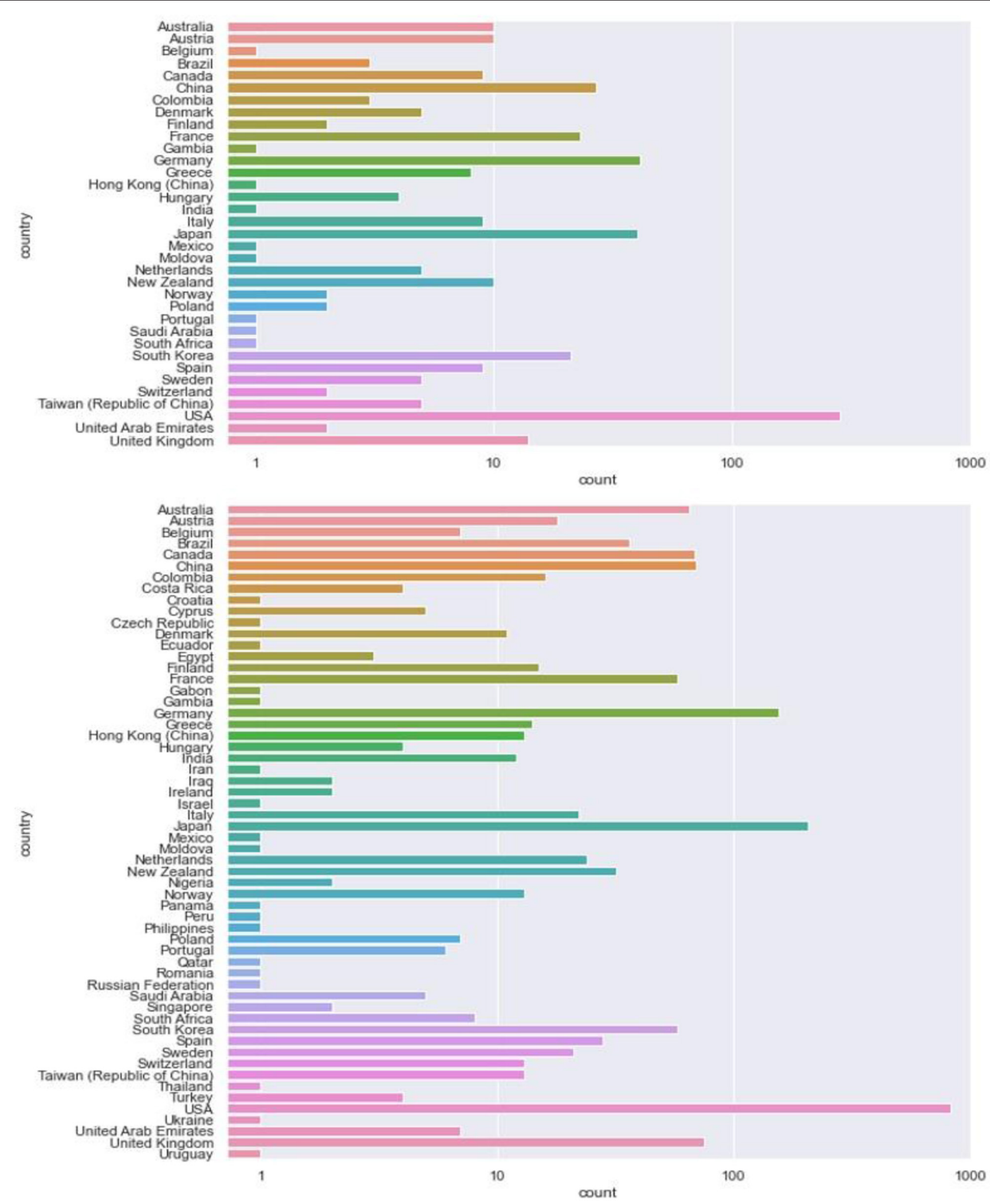

FIGURE 1 | The pool of attendees became substantially more diverse after providing free registration for the conference. Top panel represents home countries of attendees registered before free registration was offered. Bottom panel represents countries of attendees registered after free registration. 

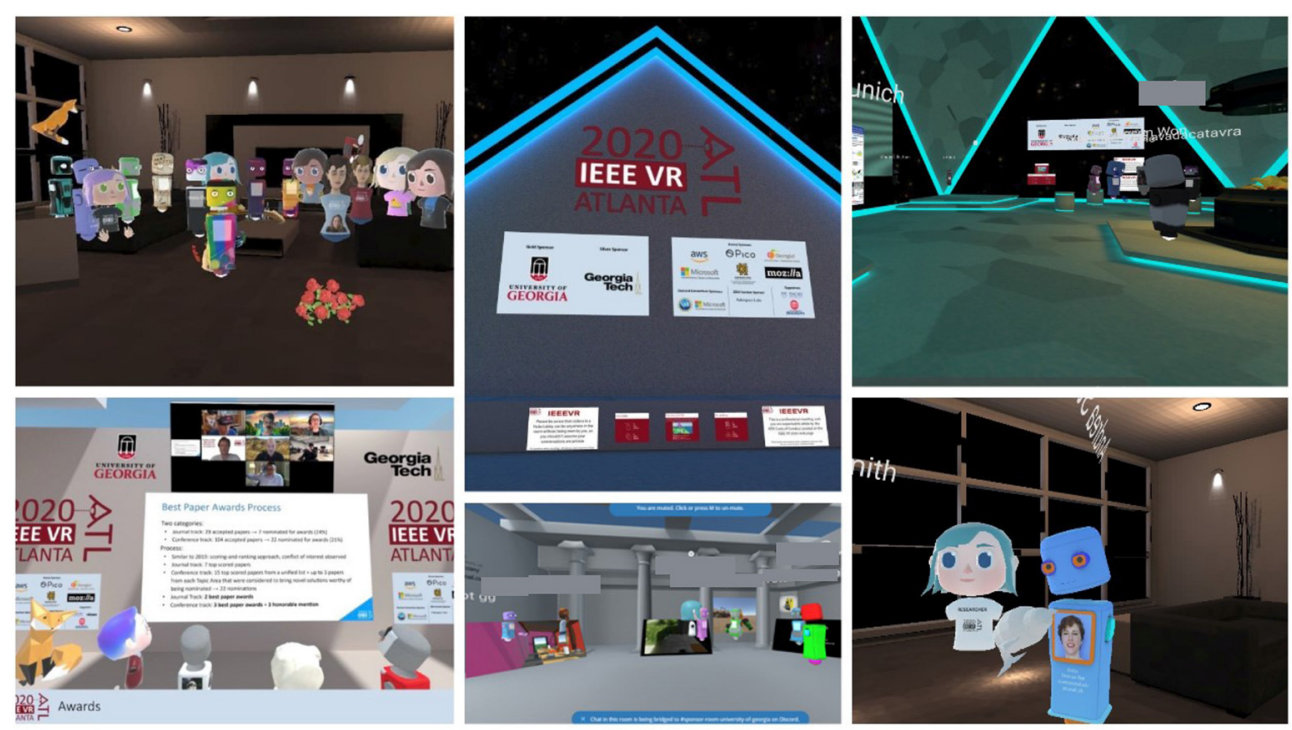

FIGURE 2 | A variety of conference activities were held in Mozilla Hubs during the IEEEVR2020 conference, including keynote speeches, talks, panels, poster sessions, networking events, and research demonstrations.

tutorial, video viewing of presented content (workshops, three talks at once streaming, track 1, track 2, track 3), poster session, and demo/3D User Interface contest. For each type of conference function, several rooms were available to regulate the number of attendees in each room (25 users maximum) for optimal graphics and spatial audio experiences. Similarly, several different types of networking function rooms were available (e.g., socializing, sponsor, and Birds of a Feather) with a variety of room options displaying different virtual aesthetics per networking function. A volunteer was stationed to "seed" the rooms in each of the socializing rooms to initiate networking and social interactions when attendees entered the room. Pre-scheduled social functions (e.g., Birds of a Feather) were announced on Twitter to promote the event.

Social presence for each of the media platforms the attendees used during the conference was measured with four 5-point Likert-type items that were adapted from earlier literature (Oh et al., 2018). Items gauged the extent to which attendees agreed to the following statements, "The other person is present," "The person I'm communicating with is close by," "Other people are really with me when we communicate," and "Someone is really "there" when communicating." The reliability of social presence measures for all media platforms were high (lowest Cronbach's $\alpha=0.86$, highest Cronbach's $\alpha=0.91)$.

Attendees' overall satisfaction with IEEEVR2020 was gauged with two items that asked whether they would like to repeat the experience of attending a conference online $(1=$ Definitely yes; 5 $=$ Definitely not), and how they rated their overall experience of IEEEVR2020 $(1=$ Very good; $5=$ Very bad $)$.

Attendees were also asked how much they would be willing to pay (in U.S. Dollars) as a presenter and as an attendee.
In an open-ended response, we also asked attendees whether they had any other feedback that they wished to share. These responses were coded and thematically analyzed (Braun and Clarke, 2012). Finally, four questions inquired about attendees' age, gender, education, and prior experience with VR (Table 1).

\section{Survey Results}

\section{Conference Activities and Effectiveness}

When asked how important the different activities were when attending a conference, attendees reported that listening to keynotes, talks, and panels was the most important activity at a conference $(M=4.32, S D=0.72)$. Socializing and building networks $(M=4.17, S D=0.86)$ and discussing research ideas with other attendees $(M=4.08, S D=0.80)$ were considered important. Learning methodological or technical skills $(M=$ $3.84, S D=0.98)$ and asking questions of presenters $(M=3.62$, $S D=0.85)$ were considered relatively unimportant activities at a conference.

Attendees thought IEEEVR2020 was most effective for listening to keynotes, talks, and panels $(M=4.30, S D=0.88)$. The next most effective activity at IEEEVR2020 was asking questions of presenters $(M=3.68, S D=1.07)$ and learning a new methodological or technical skill $(M=3.20, S D=1.10)$. Attendees felt that IEEEVR2020 was least effective at conference activities that required interactions with other attendees such as discussing research ideas $(M=2.85, S D=1.12)$, and socializing and building networks $(M=2.68, S D=1.21)$. It is interesting to note the large differences in means between the perceived effectiveness of the activities, implying that the attendees felt the virtual platform was very effective at delivering keynotes, talks, and panels, but only moderately effective at allowing them to engage in other conference activities. 
TABLE 1 | Demographic information of survey respondents.

\begin{tabular}{|c|c|}
\hline Categories & $\begin{array}{c}\text { Frequency (percentile) } \\
\text { Total } N=363\end{array}$ \\
\hline \multicolumn{2}{|l|}{ Gender } \\
\hline Female & $102(28.1 \%)$ \\
\hline Male & $253(69.7 \%)$ \\
\hline Non-binary & $1(0.3 \%)$ \\
\hline Prefer not to answer & $6(1.7 \%)$ \\
\hline \multicolumn{2}{|l|}{ Age } \\
\hline $18-25$ & $55(15.2 \%)$ \\
\hline $26-35$ & $153(42.1 \%)$ \\
\hline $36-45$ & 79 (21.8\%) \\
\hline $46-55$ & $50(13.8 \%)$ \\
\hline $56-65$ & $20(5.5 \%)$ \\
\hline $66-75$ & $4(1.1 \%)$ \\
\hline $76-85$ & $2(0.6 \%)$ \\
\hline \multicolumn{2}{|l|}{ European Union (EU) affiliation } \\
\hline Yes & 108 (29.8\%) \\
\hline No & $255(70.2 \%)$ \\
\hline \multicolumn{2}{|l|}{ Highest education } \\
\hline High school graduate/GED & $7(1.9 \%)$ \\
\hline Bachelor's degree & $66(18.2 \%)$ \\
\hline Master's degree & $130(35.8 \%)$ \\
\hline MD, JD, PhD, other advanced degree & $158(43.5 \%)$ \\
\hline \multicolumn{2}{|l|}{ Professional role } \\
\hline Undergraduate student & $13(3.6 \%)$ \\
\hline Graduate student & $109(30.0 \%)$ \\
\hline Post-doc & $25(6.9 \%)$ \\
\hline Professor & 77 (21.2\%) \\
\hline Research Scientist & 55 (15.2\%) \\
\hline \multicolumn{2}{|l|}{ Conference participation status } \\
\hline Presenter & $152(41.9 \%)$ \\
\hline Attendee & $211(58.1 \%)$ \\
\hline \multicolumn{2}{|l|}{ VR research experience } \\
\hline Yes & 329 (90.6\%) \\
\hline No & $34(9.4 \%)$ \\
\hline \multicolumn{2}{|l|}{ Years in VR experience } \\
\hline $0-2$ & 67 (20.6\%) \\
\hline $3-5$ & $113(34.8 \%)$ \\
\hline $6-10$ & 69 (21.2\%) \\
\hline $11-15$ & $21(6.5 \%)$ \\
\hline 16 or more & 55 (16.9\%) \\
\hline
\end{tabular}

\section{Media Choice and Appropriateness at IEEEVR2020}

These different levels of perceived effectiveness may be explained by the fact that the most widely used media platform during the conference (Figure 3) was Twitch $(n=302,83.2 \%)$, a livestreaming platform through which attendees had the option to view keynotes, talks, and panels. However, Twitch's capacity to encourage social interactions is limited to comments made in a real-time chat window visible as the streaming is taking place. Attendees confirmed this by indicating that Twitch seemed most appropriate for listening to keynotes, talks, and panels $(M=4.69$,

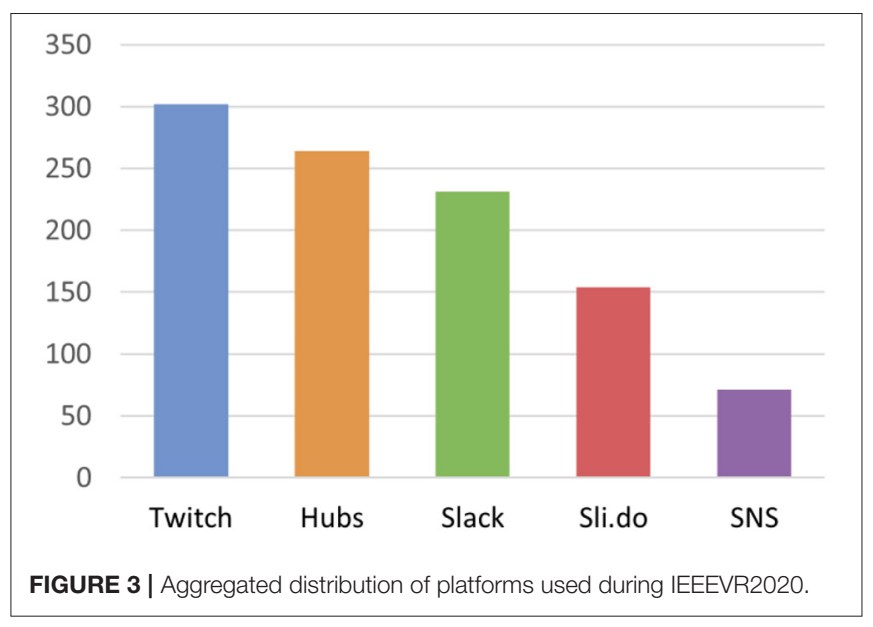

$S D=0.60)$ and was least appropriate for socializing and building networks $(M=1.70, S D=0.90)$.

The second most widely used media platform during the conference was Mozilla Hubs $(n=264,72.7 \%)$, a social VR platform that allowed users to enter and interact in the virtual world using a wide range of technology devices. Although many attendees owned a head mounted display (Yes $n=186$; No $n$ $=120$ ), of the attendees who used Hubs, 183 of them were on laptops or personal computers, 64 of them used a head mounted display to interact, two used smartphones, and three used a combination of these devices. Therefore, despite having access to a VR headset, most attendees chose to interact in Hubs on a laptop or desktop computer, $\chi^{2}(3, N=231)=31.86, p$ $<0.001$. Nevertheless, Hubs was seen as most appropriate for socializing and building networks $(M=3.69, S D=1.11)$ and least appropriate for asking questions to presenters $(M=2.83$, $S D=1.29$ ).

Slack was the third most used media platform during the conference $(n=231,63.6 \%)$. Slack, a text-based chat platform, was deemed to be most appropriate for asking questions of presenters $(M=3.48, S D=1.20)$ and least appropriate for learning a new methodological or technical skill $(M=2.38$, $S D=1.15)$. The next popular platform was Sli.do $(n=154$, $42.4 \%)$. True to its purpose, attendees felt that Sli.do was most appropriate for asking questions of presenters $(M=4.38, S D$ $=0.83$ ). Social media (e.g., Twitter, Facebook) were the least used media platform for participating in IEEEVR2020 $(n=$ $71,19.6 \%)$. Not surprisingly, attendees felt that social media were most appropriate for socializing and building networks $(M$ $=3.49, S D=1.12$ ) and least appropriate for learning a new methodological or technical skill $(M=2.03, S D=1.30)$. Table 2 presents the descriptive statistics of the importance, effectiveness, and media appropriateness of the different media platforms used during IEEEVR2020.

\section{Social Presence}

Although attendees reported that IEEEVR2020 was least effective at socializing and building networks overall, for the participants who experienced the Hubs platform, perceived social presence 
TABLE 2 | Descriptive statistics of perceptions of IEEEVR2020.

\begin{tabular}{|c|c|c|c|c|c|c|c|}
\hline \multirow[b]{2}{*}{ Conference activity } & \multirow[b]{2}{*}{ Important overall } & \multirow[b]{2}{*}{ Effective overall } & \multicolumn{5}{|c|}{ Media appropriateness } \\
\hline & & & Twitch & Hubs & Slack & Sli.do & SNS \\
\hline \multirow[t]{2}{*}{ Listening to talks } & 4.32 & 4.3 & 4.69 & 3.42 & - & - & - \\
\hline & $(0.72)$ & $(0.88)$ & $(0.6)$ & $(1.28)$ & & & \\
\hline \multirow[t]{2}{*}{ Asking questions } & 3.62 & 3.68 & 2.84 & 2.83 & 3.48 & 1.97 & 2.09 \\
\hline & $(0.85)$ & $(1.07)$ & $(1.23)$ & $(1.29)$ & $(1.20)$ & $(0.18)$ & (1.09) \\
\hline \multirow[t]{2}{*}{ Discussing research } & 4.08 & 2.85 & 1.84 & 3.54 & 3.29 & - & 2.37 \\
\hline & $(0.8)$ & $(1.12)$ & $(1.01)$ & $(1.13)$ & $(1.24)$ & & $(1.21)$ \\
\hline \multirow[t]{2}{*}{ Socializing, networking } & 4.17 & 2.68 & 1.7 & 3.69 & 3.35 & - & 3.49 \\
\hline & $(0.86)$ & $(1.21)$ & $(0.9)$ & $(1.11)$ & $(1.13)$ & & $(1.12)$ \\
\hline \multirow[t]{2}{*}{ Learning new skills } & 3.84 & 3.2 & 3.02 & 2.85 & 2.38 & - & 2.03 \\
\hline & $(0.98)$ & $(1.1)$ & (1.29) & (1.23) & $(1.15)$ & & (1.03) \\
\hline
\end{tabular}

Table shows mean values of participants' rating. Values in parentheses represent standard deviations.

was highest compared to the social presence experienced in other platforms $(M=4.13, S D=0.90)$. Over $70 \%$ of the respondents experienced Hubs at some point during the conference. Perceptions of social presence were significantly lower for all other media platforms, Twitch $(M=2.68, S D$ $=1.06)$, Slack $(M=2.57, S D=1.06)$, Sli.do $(M=2.19, S D$ $=0.98)$, and social media $(M=2.12, S D=1.01)$. Therefore, although attendees felt that IEEEVR2020 overall was not effective in assisting their efforts to socialize and build networks, Hubs seems to have elicited significantly higher levels of social presence in users relative to other media platforms. If attendees had been able to use Hubs more consistently, they may have rated the virtual conference's ability to promote social activities and build networks more highly. Figure 4 presents this data in a boxplot.

A multiple regression analysis was conducted to determine how the perceived appropriateness of Hubs for different conference activities during IEEEVR2020 (listening to keynotes, talks, and panels; socializing and building networks; discussing research ideas with other attendees; learning methodological or technical skills; asking questions of presenters) predicted social presence perception in Hubs. The five predictors explained $46 \%$ of the variance, $F_{(5,242)}=41.23, p<0.001$. Attendee's perceived appropriateness for using Hubs to socialize and build networks ( $\beta=0.43, p<0.001)$, discuss research ideas with other attendees $(\beta=0.23, p=0.002)$, and listen to keynotes, talks, and panels $(\beta=0.20, p<0.001)$ significantly predicted their perception of social presence. The other two activities, asking questions of presenters $(\beta=-0.04, p=0.46)$ and learning new methodological or technical skill $(\beta=-0.01, p=0.92)$, did not. This suggests that the latter two activities may be lower priority when designing virtual conferences in social VR spaces to maximize social presence perceptions.

\section{Overall Satisfaction With IEEEVR2020}

The respondents reported high attendance throughout the conference (Sunday $n=195$; Monday $n=259$; Tuesday $n=249$; Wednesday $n=256$; Thursday $n=230$ ). On average, participants attended 3.60 days of the 5 -day conference $(S D=1.39)$. Despite feeling that IEEEVR2020 was not sufficiently effective for some

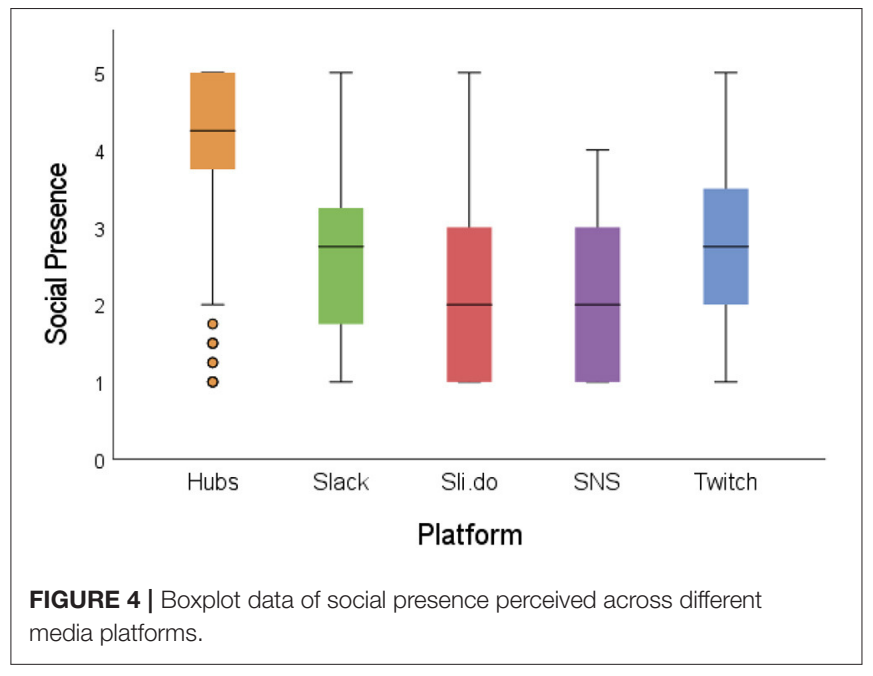

of the conference activities of the conference activities that were considered important, attendees expressed high interest in repeating the experience of attending a virtual conference $(M=$ $4.02, S D=1.05)$, and had a high overall satisfaction rate $(M=$ $4.01, S D=0.85)$.

For a more nuanced understanding of this measure of overall satisfaction, a multiple regression analysis was conducted to determine how perceived effectiveness of different conference activities during IEEEVR2020 led to overall satisfaction. The results of the regression indicated that the five predictors explained $40.2 \%$ of the variance, $F_{(5,310)}=41.76, p<0.001$. Of the five reasons for attending academic conferences, the perceived effectiveness of IEEEVR2020 in allowing attendees to socialize and build networks $(\beta=0.31, p<0.001)$, listen to keynotes, talks, and panels $(\beta=0.27, p<0.001)$, and learn a new methodological or technical skill $(\beta=0.17, p=$ 0.001 ) significantly predicted their overall satisfaction of the conference. The other two reasons, discussing research ideas with other attendees $(\beta=0.12, p=0.09)$ and asking questions of presenters $(\beta=0.05, p=0.34)$ did not significantly predict overall 
satisfaction of the conference. Attendees felt that IEEEVR2020 was the least effective in socialization and networking (section Conference Activities and Effectiveness), but it is the strongest predictor of overall satisfaction. These findings indicate that facilitating social activities and networking is one of the key areas to bolster when planning for future virtual conferences.

Overall satisfaction also differed significantly depending on whether or not attendees participated in the conference as a presenter, $F_{(1,320)}=19.06, p<0.001, \eta^{2}=0.06$. Those who participated in the conference as a presenter (e.g., talk, panel, demo, poster) were significantly less satisfied with the conference overall $(M=3.78, S D=0.90)$ than those who participated as an attendee $(M=4.19, S D=0.77)$.

\section{Willingness to Pay for Virtual IEEEVR Conferences}

Perhaps as a result of the overall satisfaction and interest in attending future virtual conferences, respondents indicated that they would be willing to pay for attending the virtual conference, both as a presenter $(M=\$ 237.86 \mathrm{USD}, S D=170.88)$ or as an attendee $(M=\$ 117.27 \mathrm{USD}, S D=117.78)$. This perceived "fair price" is notable considering that IEEEVR2020 was free to participate as an attendee, but respondents still indicated that they were willing to pay an average of $\$ 117.27$ to take part in the conference, even as an attendee.

\section{Thematic Analyses of Open-Ended Responses}

Several themes were identified following a thematic analysis of the open-ended responses collected from the survey.

\section{Fun and Playful Connections and Conversations}

A number of attendees described positive experiences when they interacted with other users in Hubs. In particular, attendees commented on the ability for Hubs interactions to be fun and playful, and appreciated the opportunity to network and socialize with other attendees: "Via Hubs, this experience was incredible. I was so impressed at how much it reflected the feeling of being at a conference in person." Another attendee mentioned the "Birds of a Feather" session in Hubs, designed to serve as an informal social gathering with a user-generated theme during IEEEVR2020: "The BOFs were super enjoyable and a real hit for learning and networking." Many felt that VR was an appropriate platform for socializing and networking activities at a conference that allowed attendees to connect. However, some attendees expressed disappointment at not finding a critical mass of users in Hubs and were frustrated by technological hurdles, "The whole experience was just annoying and a simple Zoom video session would have been so much more effective as we could actually talk to others more easily."

\section{Split Views on Posters in Hubs}

Poster sessions were often seen as the most logical and successful application of virtual conferences in the past (Erickson et al., 2011; Shami et al., 2011). During IEEEVR2020, however, attendee responses regarding poster sessions were split. Some felt that the Hubs platform was just as good as, or even better than, poster sessions at in-person conferences because they were able to present their posters using nonverbal gestures and have chance encounters with other presenters or attendees from all over the world who may have not been able to travel to an in-person conference. However, other attendees were disturbed by the lack of a large audience in the poster sessions: "It was intimidating that there were so few other people there. Most often it was just me and the presenter. At conferences I usually go see the posters with several of my colleagues and I find that much more comfortable." The attendance cap on Hubs rooms (25 maximum people) was a logistical block that appears to have moderated socialization by attendees in many room types, including for posters. Posters were spread across $\sim 50$ Hubs rooms to ensure room limits were not consistently reached and that attendees would have easy access to the room of their choice. However, this spread out poster viewer attendance and, often, made some poster rooms feel empty.

\section{New Ways to Attend Conference Talks in Hubs}

One of the most popular rooms in Hubs was the Three Talks at Once space, where attendees were able to view three streams of different talks in the same Hubs room. The experience was similar to a drive-in movie theater, where screens were spatially distanced and attendees could park themselves closer to the one of their choice. This allowed for viewing multiple streams at once, but without overlapping audio from the other streams of talks. This novel concept allowed attendees to freely fly from one talk to another in a matter of seconds and easily enjoy different parts of all three talks. There was a clear consensus in the favorable responses toward this novel way to attend conference talks. Even attendees who said that they saw little advantage in viewing video streams in Hubs were enthusiastic about the ability to "check out of the corner of my eye what was happening on the other streams." Additionally, the lobby that users spawned in became a popular place for people to discuss talks without disturbing other attendees as its distance away from the streams attenuated voice audio. The lobby served, effectively, as a movie lobby for attendees to observe activity in the streams, chat about it with others, but not impact the viewing experience of other attendees that were spatially closer to the streams.

\section{Infrastructure Challenges}

Unfortunately, visiting the Three Talks at Once space in Hubs required stable access to high speed Internet, which became a challenge for a number of the attendees, particularly during the COVID-19 pandemic when demand for high speed Internet was at an all-time high. Attendees noted their disappointment and frustration: "I think the experience would have been vastly better with a better connection, and that this was a problem with infrastructure for high-speed data in a tumultuous time." Many of the attendees said that they decided to go back to Twitch to watch the video streams after experiencing these technical frustrations.

Despite technical hurdles and infrastructure challenges, attendees noted that the virtual format of the conference provided a way for them to attend the conference even in a year with restricted travel budgets and resources: "I would not have attended IEEEVR this year at all if it would have been conventional. When it became virtual and free 
I very much wanted to attend and try to take advantage of it." Some attendees also noted climate change concerns of in-person travel and suggested that the virtual format should be implemented in future conferences even after the pandemic.

\section{FIELD OBSERVATION IN HUBS}

Seven researchers from two universities conducted a behavioral observation method to understand how conference attendees use social VR to socialize, network, and receive conference content. A coding scheme of four families and consisting of 82 total codes described conference attendee behaviors (either on web or in VR headsets) that could be observed in Hubs. Additionally, researchers conducted short interviews with random conference attendees to better understand the attendee experience.

Starting the Sunday of the conference, at least two researchers moved between different Hubs spaces to observe participants attending conference talks or socializing in social rooms. Researchers used two kinds of methods to observe participants: (1) broad observation and (2) spotlight. In broad observation, researchers generally observed the room recording codes from a coding scheme and capturing useful participant quotes. In spotlight observation, researchers picked one attendee at random and discretely observed them for $10 \mathrm{~min}$ while recording behavioral codes from the coding scheme. Both of these techniques were used for the duration of the conference across all panels, talks, breaks, and social hours for $\sim 12$ hours' worth of coding per conference day. The observational coding scheme was informed by preliminary planning meetings hosted in Hubs and meant to capture four primary categories of participant engagement: spatial (how attendees interacted in a room), interactions (how attendees interacted with each other), harassment (toxic interactions between attendees), and communication (how attendees talked about their experience). Fortunately, no instances of harassment were observed by researchers in this initiative.

\section{Field Observation Results Spatial Navigation Issues in Hubs}

Generally, over the entirety of the conference, attendees in VR had the most difficulty navigating the conference and engaging with other attendees. Navigating to other Hubs rooms often meant removing the VR headset completely, as accessing and using the virtual keyboard was too cumbersome. In fact, this was the top reason for why users indicated they were not joining Hubs in a VR headset. Many attendees had begun their Hubs experience at the start of the conference in VR but experienced difficulties with executing common conference activities. For example, networking with other attendees often involved taking note of email addresses, Twitter handles, or other contact information that the VR attendee had difficulty recording without removing the VR headset. By the last 2 days of the conference, the proportion of attendees in VR had drastically reduced with the overwhelming majority accessing Hubs on web.

\section{Evolving Interactions Over Time}

There was a marked change in interactions over the course of the conference, including from the beginning and end of any conference day and from the start to the end of conference. Sunday and Monday found many attendees with a variety of technical difficulties using Hubs, their own computers, and VR rigs. A large proportion of interactions between attendees for these early days were spent helping others (mostly strangers helping strangers) troubleshoot. In order to do so effectively, helpful conference attendees would attempt to recreate the problem the other was having, including leaving Hubs rooms to change their settings and come back to report on how to remedy the problem. By the third day of the conference, most attendees in Hubs had minor issues resolved but the morning hours found more participants with issues as compared to later in the day.

In general, over the course of the conference, attendees demonstrated more technical command of the system. At the beginning of the conference, attendees had difficulty navigating stairs, catwalks, and positioning themselves in front of the screen. On Tuesday of the conference, researchers observed teaching of the "fly" function spread rapidly through social rooms, which allowed attendees' avatars to locomote in any direction of the virtual space without having to stay on the ground. By the end of that day, there were many more attendees using that feature. By the end of the conference, most all participants were in the air observing talks using "fly." Particularly in social rooms, audio bleed was a problem that made hearing the intended conversation partner difficult. Attendees discovered they could fly up to the flight ceiling and hold conversations in relative privacy there.

\section{Limitation of Social Interactions in Hubs}

The most frequent kinds of conversations observed by researchers were participants opining that they missed the social aspects of the conference. Several times researchers overheard attendees stating that they did not go to conferences for the content, but to network with friends and colleagues they already know and make new contacts: "I create my own 'conference' in the hallways, I often miss many of the talks but the most important 'talks' are the ones I have with others outside the ballroom over coffee." Despite this overwhelming desire for social spaces, it was difficult to promote the social Hubs rooms until the third day of the conference. At that point, a sort of critical mass was achieved and there were often at least two or three attendees in the social rooms at any point in time. Paradoxically, while participants complained over different platforms (e.g., Twitter) that they missed the social aspects of the conference, by the end of the conference day Hubs participation had dropped significantly with most participants moving to less social platforms, like Twitch, to finish off the conference day.

Another hurdle for social interactions in Hubs was that the attendees' mental model of audio was in conflict with the reality of the system. Researchers overheard several conversations about private, intimate details of attendees' lives in conversations intended for only one other attendee. It appeared as if the speakers did not realize their conversation could be heard from across a room. Additionally, during talks there were several instances of disruptive conversations that participants were 
having while the speaker was presenting. Again, it appeared the speakers did not understand that even with spatial audio, their conversations could be heard throughout the room up to a certain distance.

\section{Successful Social Interactions in Hubs}

However, when the social interactions were successful in Hubs, it was extremely well-received. The Birds of a Feather social rooms, which invited attendees to host their own informal social event in Hubs, were very successful, based on numbers of attendees and comments overheard. Of note, the Women in MR social was the most playful, colorful, and boisterous social of them all. Participants even created evening wear for their avatars for the social and virtual objects were dropped in the room such as sushi boards, charcuterie plates, and wine to roughly simulate a traditional post-conference social. As the social progressed, bouquets of flowers, puppies, and other random objects were dropped in for fun. By the end of the social, the room was littered with selfie and "we"fie photos (group selfie). For example, when a conference organizer commented that, had the conference been in-person, the banquet would have taken place at the Georgia Aquarium with a beluga experience for attendees. Shortly, a beluga model was dropped into the room and participants took turns taking pictures with it. Some attendees felt that networking was easier in Hubs than in-person conferences: "Easy to approach people that you don't know, feels less intimidating, for instance easier to join conversation than in physical presence usually more difficult to get into that circle."

\section{Democratization of Academic Conferences}

Other comments heard by participants at the conference were around gratitude for the accessibility of attending the conference in this way. Several participants in countries with poor access to affordable flights stated they would not have been able to attend the conference if they had to travel to it, and several participants (particularly self-employed) said they would not have had funds to complete travel and pay the registration fees for the conference. In a similar vein, many participants stated that they were sad to miss out on a trip to a new place but also glad to have the time to spend with their family and contribute to shared household work that would normally be disrupted by conference travel. This implies that virtual conference formats may lower entry barriers for parents and caregivers who may struggle with the resources and logistics necessary for travel.

In addition, a notable difference of this virtual conference from in-person IEEEVR conferences was the sheer number of VR enthusiasts attending from the general public, instead of the traditional mix of mostly academic and industry participants. Several attendees with wide social media followings had promoted the event, which may account for the high number of attendees from the general public attending the conference. These general public attendees made comments indicating confusion about the format, purpose, and composition of the conference and seemed unaware that it was primarily an academic conference.

The removal of most status and affiliation cues by being represented through avatars in Hubs produced interactions that would have been much less likely in a traditional in-person conference (Bailenson et al., 2006). For example, researchers observed many spontaneous heated discussions and arguments between general public attendees and academic figureheads of the VR field over a variety of topics, including ethics and privacy in VR, utility and design of social VR spaces, and the strengths and drawbacks of virtual conferences. The diversity of attendees that was atypical for academic conferences also diversified the opinions introduced both in panel discussions and information conversations during social events. Research on interdisciplinary team science demonstrates that task-related diversity yields positive impact on synergistic outcomes and task performance (Horwitz and Horwitz, 2007). Given that one of the main goals of academic conferences is to inspire new and innovative ideas through synergistic interactions among attendees, the diversification of attendee profiles by including a large number of non-academic attendees from the general public may have been beneficial for academics by motivating them to widen their research perspectives.

\section{DISCUSSION AND RECOMMENDATIONS FOR FUTURE VIRTUAL CONFERENCES}

Based on a rich collection of quantitative and qualitative feedback from 363 respondents and field observations of all attendees participating in the IEEEVR2020 conference, our findings echo earlier studies that have hinted at the potential of virtual conferences (Erickson et al., 2011; Shami et al., 2011; Shirmohammadi et al., 2012; Gunkel et al., 2018). More importantly, they yield critical insights for hosting virtual conferences as standalone events, rather than as an add-on element to support the main in-person event. Hosting virtual conferences as a standalone event rather than a supplement to an in-person event would address the shortcomings of virtual conferences noted in earlier studies as well as in the current study. One critical issue with hybrid conferences is that attendees are likely to focus on either the in-person or virtual event, because they may not have the bandwidth to attend to both. Given that the benefits of conferencing, including learning new research findings and building social networks, are contingent upon a critical mass of academics attending the event, hybrid conferences are likely to diminish the benefits of attending academic conferences. Below, we present a list of recommendations and points for consideration for future virtual conferences with theoretical and practical implications to consider even after moving beyond the COVID19 pandemic.

\section{Social Presence May Not Be the Main Attraction Point for Social VR}

Academic discourse on the appropriateness of media platforms for certain tasks have often conflated media richness with media effectiveness. That is, the theoretical assumption has often been that when media platforms are able to deliver rich layers of sensory cues (e.g., VR), they result in "better" interactions and communication outcomes than relatively leaner media (e.g., textbased chat) (Short et al., 1976; Trevino et al., 1987; Rice, 1993). 
Similar logic has been applied to our understanding of VR and how it impacts interaction outcomes, wherein VR experiences are often assumed to be more effective than non-VR experiences because the rich sensory cues of VR experiences are thought to lead to presence, resulting in desirable communication and interaction outcomes (Slater and Wilbur, 1997; Slater and Steed, 2000; Biocca et al., 2003). The discourse on interactions in social VR has rested on the same foundation, with the assumption that high social presence produces more favorable interaction outcomes than less immersive media platforms (Oh et al., 2018).

However, our findings from the survey and field observation in Hubs point to a more complicated and nuanced explanation of social presence and media selection that echoes recent scholarship on the relationships among media platforms, social situations, and users (Van Den Hooff et al., 2005). Media appropriateness is not determined solely by the objective match between features capabilities (i.e., what the platform can do) and task requirements (i.e., what the user needs), or driven mainly by user experience or expertise, as previously thought. Social context and shared meanings of media platforms within work groups seem to also serve as important predictors of technology use (Fulk, 1993; Markus, 1994).

For instance, our survey data indicate that attendees felt that Hubs was most appropriate for socializing and building networks and least effective for asking questions of presenters. They felt the highest levels of social presence on Hubs compared to other media platforms, but their understanding of which conference activities they thought Hubs was most appropriate for predicted their perception of social presence. Based on these findings, future virtual conferences may want to consider using social VR platforms mainly as a means for socializing and building networks, while providing other platforms to address other conferencing needs. Even when Hubs could easily be used to ask questions or other presenters or to learn new research methodologies or techniques, attendees felt that Hubs was not very appropriate for these activities, nor did these activities lead to perceptions of social presence, even when they involved interactions with other attendees in Hubs.

Another example of the rift between what platforms can do and what attendees want is demonstrated by the fact that, despite over $60 \%$ of respondents owning their own VR headsets, only a third of them ended up using the headset to interact within Hubs, with the majority choosing to use their laptop or desktop computers to participate in Hubs. Also, although the bulk of attendees had high expertise and experience with VR, Twitch was the most popular media platform during IEEEVR2020 despite the attendees' explicit desires for social interaction and their clear understanding of Twitch's limited capacity to deliver it. These behaviors may seem counterintuitive because most of the attendees reported feeling the highest levels of social presence in Hubs relative to other media platforms available during the conference, particularly when they were using VR headsets. However, for virtual conferences, attendees seem to need the flexibility that lower immersive platforms provide (e.g., Twitch) so that they may tend to both virtual and physical tasks instead of committing to the complete engagement required when using VR headsets.
Counter to the frameworks that emphasize the importance of media richness, VR, even with all of its potential as an immersive and interactive communication platform, eliciting the highest level of social presence in users, was still not equipped to meet the social requirements of an academic conference, particularly when most of the attendees were participating in the conference from their homes. Attendees who attempted to interact with others in VR with a headset quickly found that they had to frequently remove the headset to visit another room, write down another attendee's contact information, or tend to family needs at home. The headsets were also uncomfortable to wear for an extended period of time and may have induced physical and mental fatigue after extensive use. Some attendees commented that watching keynotes and talks were not an "optimal use of VR." The current findings imply that VR headsets bring about a sense of novelty and high perceived social presence, but much work is needed to improve the users' experience of social interactions within the virtual worlds.

The findings also suggest that attendees exhibit fundamentally different orientations and expectations toward in-person vs. virtual conferences. For in-person conferences where attendees must leave their daily lives to travel to a remote location, attendees are typically so engrossed in conference activities that they find it difficult to tend to the virtual elements that took place in tandem with the in-person conference (Anderson and Mason, 1993; Shirmohammadi et al., 2012). In contrast, when the conference is held virtually, attendees may not make (and may not wish to make) the same travel and caregiving accommodations necessary for in-person conferences and may need to tend to their daily lives in addition to participating in the conference. Requiring the same travel and caregiving accommodations for both in-person and virtual conferences seems unrealistic; understanding the complexity of platform capabilities, task requirements, as well as the realistic constraints of various social contexts will be critical in designing effective virtual conferences.

\section{Multi-Platform Availability: A Double-Edged Sword}

A logical solution to the paradox of social presence in virtual conferences may be to provide a wide range of communication platforms so that attendees have the option of selecting the platform most appropriate for their task and situation. IEEEVR2020 attendees demonstrated a clear preference toward using a combination of different media platforms to address varying needs and to cope with changing environmental and situational constraints, and appreciated the flexibility to do so. Even users who are well-versed in using a communication technology can encounter situational constraints out of their control, such as time zone differences, that shift the seemingly objective fit between the task and the media platform. This may explain why many attendees resorted to asynchronous communication through Slack rather than the synchronous communication in Hubs. The difficulty of hosting a virtual conference with attendees located in different time zones around the world has also been discussed in earlier studies on virtual 
conferences which only used social VR as a means to participate remotely (Erickson et al., 2011; Shami et al., 2011). A multiplatform approach resolves many of these issues and allows attendees to overcome situational constraints that can negatively impact the conference experience.

However, IEEEVR2020 also suffered from providing too many platform choices to attendees, thereby spreading the participation sparsely and failing to create a critical mass on any of the platforms. This may be why the attendees made negative comments regarding the absence of social interaction on nonHubs channels (e.g., Slack) or noting the lack of participation in the Hubs rooms. Given that academic conferences benefit attendees by creating a common, shared space that is conducive to synergistic interactions among a large and diverse group of people, the lack of a critical mass of attendees across the different platforms may be one of the most critical drawbacks of IEEEVR2020. Future virtual conferences need to consider striking a careful balance between providing flexibility and choice to attendees, while retaining sufficient structure that sets up a common, shared space for a critical number of attendees to interact with each other. This balance may have arisen organically during IEEEVR2020, where most attendees used Twitch (mainly for watching talks), Hubs (mainly for socializing), and Slack (mainly for asking questions to other attendees). In time, the development of a new platform dedicated for virtual conferences that converges the features of different communication platforms may provide a more streamlined solution.

\section{Provide Unique Added Value of Virtual Conferences}

For virtual conferences to be adopted as viable event venues even after the COVID-19 pandemic, they need to provide added value that is unique to virtual conferences. That is, if the virtual conference is a mere replica of an in-person conference, its utility is limited in that virtual platforms do not currently replicate the nuances of in-person social interactions and attendees will almost always prefer the in-person event. Therefore, conference planners should design and present virtual conferences that leverage features of digital communication platforms and offer benefits that are unique to virtual participation. In particular, attendees noted that the two most important conference activities are attending research talks and socializing with attendees. Virtual conferences need to be designed so that they allow attendees to tend to these tasks by leveraging unique features of virtual interactions.

The best moments of IEEEVR2020, according to attendee responses, were when the virtual conference was able to overcome the limitations of in-person events in unique and creative ways, afforded by the features of the platform. For instance, the Three Talks at Once space allowed attendees to transcend the spatial boundaries of in-person academic conferences by allowing avatars to fly seamlessly from one session to another by introducing three talk spaces in the same Hubs space, separated by sufficient distance for spatial audio to fade out when leaving one talk to go to another. This feature allowed participants to attend multiple talks taking place at the same time by flying in and out of the talk spaces, which would have been significantly more difficult to do in a physical space. Similarly, attendees who viewed the talks through Twitch also noted the ease with which they were able to investigate the content of multiple talks at once with a click of a button. Another popular feature in the virtual conference was the Birds of a Feather session, which invited any attendee to set up a Hubs room and designate a theme for a social get-together. The ease of setting up and sharing a virtual space for these meetings allowed for spontaneous meetings of attendees with a common area of interest. This form of spontaneity would not be possible at in-person meetings, where reserving and preparing a physical space for a meeting would involve much more elaborate planning ahead of time. Similarly, future virtual conferences should consider what the unique value of the virtual format is, rather than treating virtual conferences as a placeholder for the in-person event.

\section{People Have Little Patience for Technical Frustrations}

Because of their prior experience with and expertise in VR, the attendees of IEEEVR2020 are likely to have high levels of patience with technical frustrations when it comes to learning to use different communication platforms. This patience was evident in the way attendees quickly learned to navigate and use the space effectively for communication and social interactions during the conference despite initial difficulties. However, even with this group of people, a large number of attendees noted experiencing frustration at technological and infrastructure issues, such as spatial audio problems and internet connectivity issues, which drove them to lower immersive platforms like Twitch and Slack rather than Hubs.

When attendees have lower thresholds for technical frustrations, they are less likely to invest sufficient time for computer mediated social interactions, and some attendees lamented the lack of social interactions during IEEEVR2020. Prior studies demonstrate that less time spent on computermediated social interactions can lead to lower quality of communication, wherein interactants are less able to gather sufficient information about each other to satisfactorily continue the interaction (Walther, 2015). Again, less time spent on engaging in conference activities implies overall diminishing returns for attendees. Therefore, future virtual conferences need to be cognizant of the low threshold for technical frustrations, even among attendees with relatively high levels of experience and expertise, and implement creative means to maximize their time invested in interacting with others during the conference.

Based on the survey data, technical frustrations were experienced more intensely by people who participated in IEEEVR2020 as a presenter, who reported being significantly less satisfied with the overall conference experience. This is a critical point to consider for expanding attendance rates of future virtual conferences. Presenters who were frustrated and dissatisfied with their virtual conference experience are less likely to try out another virtual conference, leading to a drop in participation. 
To maintain a critical mass attending virtual conferences, future conference organizers may want to consider several approaches to reduce frustrations regarding technical barriers specifically for presenters, such as tutorial sessions dedicated to presenters, or easy-to-access troubleshooting resources during the conference.

\section{Open Up the Academic Conference}

Perhaps most importantly, hosting IEEEVR2020 as a standalone virtual conference served as an important step forward in democratizing academic conferences and increasing accessibility to the knowledge produced for both academics and nonacademics. The number of registered attendees rose from $\sim 500$ in 2019 to over 2,000 in 2020 , the countries from which the attendees hailed became more diverse (Figure 1), and the participation rate of non-academic attendees increased dramatically. Typically, rigorous peer-reviewed publications are protected by paywalls, conferences charge prohibitively high registration fees for non-members, attendees need to travel for several days to a remote location to participate, and academic knowledge and social capital continue to remain siloed among select academics in their respective disciplines who have access to these resources. Even among academics, equity is an ongoing issue; female academics, in particular, fulfill the majority of caregiving responsibilities at home and often face professional disadvantages because they are unable to travel to in-person meetings (Holmes et al., 2016; Cardel et al., 2020).

Virtual conferences without in-person requirements allow conference organizers to substantially reduce registration fees and lessen participation costs for attendees, such as travel and hotel fees. The perceived fair price for attending a virtual conference as a presenter (average \$237.86) and an attendee (\$117.27) is substantially lower than what participants pay for in-person conferences $(\sim \$ 1,000)$ and would allow a much more diverse range of individuals to attend. As we saw with IEEEVR2020, the free virtual format encouraged higher participation ratios of female attendees, non-academics, graduate and undergraduate students, and generally served to diversify the attendee pool. Future conferences should make a conscious effort to secure feedback from diverse attendees, including those who may have little experience with academic research, to expand and diversify the attendee pool. Democratizing the academic knowledge-sharing process can help to disseminate state-of-the-art research findings widely across the discipline and to the general public. This is likely to promote the translation of academic research into actionable policy and practice.

\section{REFERENCES}

Abbey, J. R., and Link, C. K. (1994). "The convention and meeting sector - its operation and research need," in Travel, Tourism and Hospitality Research, eds J. R. B. Ritchie and C. R. Goeldner (New York, NY: Wiley), 273-284.

Anderson, T., and Mason, R. (1993). International computer conferencing for professional development: the bangkok project. Am. J. Distance Educ. 7, 5-18. doi: 10.1080/08923649309526819

\section{CONCLUSION}

As one of the largest academic conferences that was hosted as a completely virtual event, the IEEEVR2020 conference provided valuable insights into the promises and shortcomings of virtual conferencing. Over time, technological advancements are likely to provide further opportunities and overcome some of the shortcomings discussed in the current study. However, the fundamental motivations that drive academics to communicate, interact, and create networks is likely to remain unchanged. The current findings serve to highlight the unique benefits of standalone virtual conferences that may serve such motivations in ways that in-person events cannot fulfill, and are widely applicable to any academic field that has hosted an in-person gathering in the past. The COVID-19 global pandemic catalyzed the launch of a completely virtual conference for IEEEVR2020, but current findings suggest that academics should continue to consider virtual conferences as a viable means to share and disseminate academic knowledge, even after the travel restrictions have been lifted.

\section{DATA AVAILABILITY STATEMENT}

The data supporting the conclusions of this article will be made available by the authors upon request.

\section{ETHICS STATEMENT}

The studies involving human participants were reviewed and approved by University of Georgia Institutional Review Board. The patients/participants provided their written informed consent to participate in this study.

\section{AUTHOR CONTRIBUTIONS}

SA and LL conceived the study idea, planned the data collection, collected data, and analyzed the results. SA, LL, AE, AW, BM, and $\mathrm{KJ}$ designed the study. SA and LL wrote the manuscript with support from AE, AW, BM, and KJ. All authors contributed to the article and approved the submitted version.

\section{FUNDING}

This material was based upon work supported by the National Science Foundation under Grant Number 2032474. Any opinions, findings, and conclusions or recommendations expressed in this material are those of the authors and do not necessarily reflect the views of the National Science Foundation.

Bailenson, J. N., Yee, N., Merget, D., and Schroeder, R. (2006). The effect of behavioral realism and form realism of real-time avatar faces on verbal disclosure, nonverbal disclosure, emotion recognition, and copresence in dyadic interaction. Presence Teleoperat. Virtual Environ. 15, 359-372. doi: 10.1162/pres.15. 4.359

Barnes, M. D., Wykoff, R., King, L. R., and Petersen, D. J. (2012). New developments in undergraduate education in public health: implications for 
health education and health promotion. Health Educ. Behav. Off. Publ. Soc. Public Health Educ. 39, 719-724. doi: 10.1177/1090198112464496

Biocca, F., Harms, C., and Burgoon, J. K. (2003). "Toward a more robust theory and measure of social presence: review and suggested criteria," in Presence: Teleoperators and Virtual Environments, Vol. 12. (Cambridge, MA: MIT Press), 456-480. doi: 10.1162/105474603322761270

Braun, V., and Clarke, V. (2012). "Thematic analysis," in APA Handbook of Research Methods in Psychology, eds H. Cooper, P. M. Camic, D. L. Long, A. T. Panter, D. Rindskopf, and K. J. Sher (American Psychological Association), 57-71. doi: 10.1037/13620-004

Cardel, M. I., Dhurandhar, E., Yarar-Fisher, C., Foster, M., Hidalgo, B., McClure, L. A., et al. (2020). Turning chutes into ladders for women faculty: a review and roadmap for equity in academia. J. Women's Health 29, 721-733. doi: 10.1089/jwh.2019.8027

Edelheim, J. R., Thomas, K., Åberg, K. G., and Phi, G. (2018). What do conferences do? what is academics' intangible return on investment (ROI) from attending an academic tourism conference? J. Teaching Travel Tourism 18, 94-107. doi: $10.1080 / 15313220.2017 .1407517$

Erickson, T., Sadat Shami, N., Kellogg, W. A., and Levine, D. W. (2011). Synchronous interaction among hundreds: an evaluation of a conference in an avatar-based virtual environment. Conference Hum. Fact. Comput. Syst. Proc. 13, 503-512. doi: 10.1145/1978942.1979013

Foley, C., Edwards, D., and Schlenker, K. (2014). Business events and friendship: leveraging the sociable legacies. Event Manage. 18, 53-64. doi: $10.3727 / 152599514 X 13883555341887$

Fulk, J. (1993). Social construction of communication technology. Acad. Manage. J. 36, 921-950. doi: 10.2307/256641

Goetz, T., Hall, N. C., Frenzel, A. C., and Pekrun, R. (2006). A hierarchical conceptualization of enjoyment in students. Learn. Instr. 16, 323-338. doi: 10.1016/j.learninstruc.2006.07.004

Gunkel, S. N. B., Stokking, H. M., Prins, M. J., van der Stap, N., ter Haar, F. B., and Niamut, O. A. (2018). "Virtual reality conferencing: multi-user immersive VR experiences on the web," in Proceedings of the 9th ACM Multimedia Systems Conference on - MMSys'18 (Amsterdam: ACM Press), 498-501. doi: 10.1145/3204949.3208115

Holmes, M. H., Jackson, J. K., and Stoiko, R. (2016). Departmental dialogues: facilitating positive academic climates to improve equity in STEM disciplines. Innovative Higher Educ. 41, 381-394. doi: 10.1007/s10755-016-9358-7

Horwitz, S. K., and Horwitz, I. B. (2007). The effects of team diversity on team outcomes: a meta-analytic review of team demography. J. Manage. 33, 987-1015. doi: 10.1177/0149206307308587

Høyer, K. G., and Næss, P. (2001). The ecological traces of growth: economic growth, liberalization, increased consumption - and sustainable urban development? J. Environ. Policy Plan. 3, 177-192. doi: 10.1002/jepp.84

Jamison, L. (2017). Second Life Still Has 600,000 Regular Users - The Atlantic. Available online at: https://www.theatlantic.com/magazine/archive/2017/12/ second-life-leslie-jamison/544149/ (accessed December 9, 2020).

Le, D. A., MacIntyre, B., and Outlaw, J. (2020). "Enhancing the experience of virtual conferences in social virtual environments," in 2020 IEEE Conference on Virtual Reality and 3D User Interfaces Abstracts and Workshops (VRW) (Atlanta, GA), 485-494. doi: 10.1109/VRW50115.2020.00101

Leong, J. J., Kinross, J., Taylor, D., and Purkayastha, S. (2008). Surgeons have held conferences in second life. BMJ. 337:a683. doi: 10.1136/bmj.a683

Mair, J., and Frew, E. (2018). Academic conferences: a female duo-ethnography. Curr. Issues Tourism 21, 2160-2180. doi: 10.1080/13683500.2016.1248909

Mair, J., and Thompson, K. (2009). The UK association conference attendance decision-making process. Tourism Manage. 30, 400-409. doi: 10.1016/j.tourman.2008.08.002

Markus, M. L. (1994). Electronic mail as the mediumof managerial choice. Org. Sci. 5, 502-527. doi: $10.1287 /$ orsc.5.4.502

Nevins, J. (2014). Academic jet-setting in a time of climate destabilization: ecological privilege and professional geographic travel. Professional Geographer 66, 298-310. doi: 10.1080/00330124.2013.784954

Oester, S., Cigliano, J. A., Hind-Ozan, E. J., and Parsons, E. C. M. (2017). Why conferences matter: an illustration from the International Marine Conservation Congress. Front. Mar. Sci. 4:257. doi: 10.3389/fmars.2017.00257
Oh, C. S., Bailenson, J. N., and Welch, G. F. (2018). A systematic review of social presence: definition, antecedents, and implications. Front. Robot. AI. 5:114. doi: 10.3389 /frobt.2018.00114

Parsons, E. C. M. (2015). So you think you want to run an environmental conservation meeting? advice on the slings and arrows of outrageous fortune that accompany academic conference planning. J. Environ. Stud. Sci. 5, 735-744. doi: 10.1007/s13412-015-0327-8

Rice, R. E. (1993). Media appropriateness. Hum. Commun. Res. 19, 451-484. doi: 10.1111/j.1468-2958.1993.tb00309.x

Rogers, T. (2012). Conferences and Conventions. Abingdon: Routledge. doi: $10.4324 / 9780203119402$

Shami, N. S., Erickson, T., and Kellogg, W. A. (2011). "Common ground and small group interaction in large virtual world gatherings," in ECSCW 2011: Proceedings of the 12th European Conference on Computer Supported Cooperative Work, 24-28 September 2011, Aarhus Denmark. doi: 10.1007/978-0-85729-913-0_21

Shirmohammadi, S., Hu, S.-Y., Ooi, W. T., Schiele, G., and Wacker, A. (2012). "Mixing virtual and physical participation: the future of conference attendance?," in 2012 IEEE International Workshop on Haptic Audio Visual Environments and Games (HAVE 2012) Proceedings (Munich: IEEE), 150-155. doi: 10.1109/HAVE.2012.6374455

Short, J. A., Williams, E., and Christie, B. (1976). The Social Psychology of Telecommunications. London: Wiley.

Slater, M., and Steed, A. (2000). A virtual presence counter. Presence Teleoperat. Virtual Environ. 9, 413-434. doi: 10.1162/105474600566925

Slater, M., and Wilbur, S. (1997). A framework for immersive virtual environments (FIVE): speculations on the role of presence in virtual environments. Presence Teleoperat. Virtual Environ. 6, 603-616. doi: 10.1162/pres.1997.6.6.603

Sousa, B. J., and Clark, A. M. (2017). Getting the most out of academic conference attendance. Int. J. Qualitative Methods 16:160940691774044. doi: $10.1177 / 1609406917740441$

Trevino, L. K., Lengel, R. H., and Daft, R. L. (1987). Media symbolism, media richness, and media choice in organizations: a symbolic interactionist perspective. Commun. Res. 14, 553-574. doi: 10.1177/0093650870140 05006

U.S. Travel Association (2017). Economic Impact of Meeting and Business Events. Available online at: https://www.ustravel.org/system/files/media_root/ document/Research_Fact-Sheet_Meetings-Mean-Business_2017.pdf (accessed September 8, 2020).

Van Den Hooff, B., Groot, J., and De Jonge, S. (2005). Situational influences on the use of communication technologies: a meta-analysis and exploratory study. J. Bus. Commun. 42, 4-27. doi: 10.1177/0021943604271192

Walther, J. B. (2015). "Social information processing theory (CMC)," in The International Encyclopedia of Interpersonal Communication, eds C. R. Berger, and M. E. Roloff (Wiley), 1-13. doi: 10.1002/9781118540190.wbeic192

Witt, S. F., Sykes, A. M., and Dartus, M. (1995). Forecasting international conference attendance. Tourism Manage. 16, 559-570. doi: 10.1016/0261-5177(95)00079-8

Yoo, J. J. E., and Zhao, X. (2010). Revisiting determinants of convention participation decision making. J. Travel Tourism Marketing 27, 179-192. doi: 10.1080/10548401003590369

Zhang, H. Q., Leung, V., and Qu, H. (2007). A refined model of factors affecting convention participation decision-making. Tourism Manage. 28, 1123-1127. doi: 10.1016/j.tourman.2006.07.008

Conflict of Interest: The authors declare that the research was conducted in the absence of any commercial or financial relationships that could be construed as a potential conflict of interest.

Copyright (c) 2021 Ahn, Levy, Eden, Won, MacIntyre and Johnsen. This is an openaccess article distributed under the terms of the Creative Commons Attribution License (CC BY). The use, distribution or reproduction in other forums is permitted, provided the original author(s) and the copyright owner(s) are credited and that the original publication in this journal is cited, in accordance with accepted academic practice. No use, distribution or reproduction is permitted which does not comply with these terms. 